\title{
EXPERIMENTALLDADE: CIENCIA, CAPITAL E PODER NO MUNDO DOS ENSAIOS CLÍNICOS
}

\author{
Adriana Petryna \\ University of Pennsylvania - Estados Unidos
}

Resumo: A terceirização e expatriação de ensaios clínicos abriram um campo de atividade experimental sem precedentes. Este ensaio discute os mecanismos cientificos e regulatórios através dos quais um campo global de experimentalidade se configura. Ele mapeia a indústria de ensaios clínicos e seu deslocamento para países de média e baixa renda (especialmente o Leste Europeu e o Brasil). Enquanto o empreendimento de ensaios clínicos se adapta a normas regulatórias nacionais e internacionais, o reconhecimento de riscos prejudiciais a pacientes e populações é frequentemente adiado ou evitado. Este texto explora as brechas legais em relação a como os benefícios e riscos desse empreendimento são calculados, bem como as práticas emergentes de responsabilidade.

Palavras-chave: bioética, ensaios clínicos, ética de pesquisa, indústria farmacêutica.

Abstract: The outsourcing and offshoring of clinical trials have sparked an unprecedented field of experimental activity. This essay addresses the scientific and regulatory mechanisms by which a global field of experimentality takes form. It charts a clinical trials industry and its move to low-and middle-income countries (particularly in Eastern Europe and Brazil). As the clinical trials enterprise adapts itself to international and national regulatory norms, the acknowledgement of adverse risks to patients and populations is often deferred or engineered out. The essay explores policy gaps with respect to how benefits and liabilities of this enterprise are weighed as well as emergent practices of accountability.

Keywords: bioethics, clinical trials, global pharmaceuticals, research ethics.

\footnotetext{
* Agradeço a João Biehl pelos insights, a Ethon Fonseca pela tradução e a Mariana Socal pelo auxílio editorial neste artigo, que foi adaptado do meu livro When experiments travel: clinical trials and the global search for human subjects (Petryna, 2009).
} 
Nas duas últimas décadas, a experimentação com seres humanos se deslocou das esferas mais exclusivas da medicina acadêmica e se expandiu para os locais de atendimento médico cotidiano. Com a biotecnologia e a genética beirando uma revolução na medicina, cada vez mais pessoas nos Estados Unidos e outros países estão prontas para assumir riscos que desconhecem para entrar na nova era. Contra um pano de fundo de pandemias como HIV/ AIDS, a pesquisa clínica ocorre em uma dimensão global e em contextos onde experimentos se tornaram a única opção de sobrevivência. Em lugares onde doenças graves e crônicas se misturam a transições políticas, guerras civis, turbulência civil e pobreza, a linguagem de crise tornou-se instrumental, dando legitimidade à experimentação que, em outras circunstâncias, seria negada. Alguns observadores alegam que experimentos e tratamentos experimentais só podem trazer benefícios nesses contextos de desespero e que a pesquisa vem para preencher o vazio quando as agências governamentais fornecem pouco ou nenhum serviço de saúde. Seja nos espaços confinados e regulados da clínica ou no jogo da experimentação, onde se apostam vidas em muitas partes conturbadas do globo, os critérios para avaliar diferenças entre tratamentos experimentais e tratamentos padronizados vão sendo rearticulados constantemente. Não existe um único padrão, lei, regulação ou mecanismo de supervisão capaz de acompanhar a diversidade de contextos nos quais a experimentação ocorre.

O presente artigo considera as novas geografias de capital e poder que permitem que as companhias farmacêuticas exportem suas atividades de pesquisa para países de média e baixa renda e a maneira complicada como estudos clínicos tornaram-se parte integral dos serviços médicos e de saúde pública nesses contextos. O panorama da pesquisa farmacêutica e da participação em testes está mudando. Como ele muda e como a ética se ajusta a fim de justificar uma expansão massiva da pesquisa comercial em sujeitos humanos são as questões centrais desta investigação. Como a linha divisória entre os tratamentos padronizados e experimentais está se deslocando? Como estão sendo reconfiguradas as hierarquias entre seres humanos diferenciados (de acordo com sexo, raça e classe, por exemplo) e sujeitos de pesquisa em um campo médico predominantemente comercial? Na ausência de outras formas de assistência médica, será que os ensaios clínicos se tornaram "opção de tratamento preferencial para os pobres?" (Farmer, 2002). Com quais implicações para a justiça e para a governança? Enquanto os mercadores de estudos 
operam com transparência, suas práticas marcam o lugar onde a política deixa de perceber os riscos que acompanham a experimentalidade global.

A revista Fortune 500 lista a indústria farmacêutica como uma das indústrias mais lucrativas dos Estados Unidos. Até 2008, o mercado mundial de produtos farmacêuticos alcançava US\$ 900 bilhões. Esse crescimento fenomenal de mercados vem junto com o aumento igualmente sem precedentes do número de pessoas que participam em pesquisas de medicamentos. Conforme a Food and Drug Administration (FDA), a principal agência regulamentadora de medicamentos, aparelhos médicos e produtos biológicos usados pelos americanos, houve 6079 novos estudos entre 1981 e 1985, 16.435 novos estudos entre 1991 e 1995 e 36.839 novos estudos entre 2001 e 2004 (CenterWatch, 2005).

Um empresário americano que coordena testes com medicamentos para companhias farmacêuticas no exterior caracterizou o vínculo entre o crescimento do mercado farmacêutico e o aumento da pesquisa clínica em termos de uma dependência econômica complexa:

Se um médico ou enfermeiro perguntasse se você aceitaria incluir um membro da família em um ensaio clínico e se não fosse uma questão de vida ou morte, você o faria? Provavelmente a resposta seria não. O fato é que todos nós, pesquisadores e consumidores de medicamentos, estamos economicamente dependentes de outras pessoas que aceitam dizer "sim".

Novos grupos dentro dos EUA estão sendo procuradas para participar como sujeitos de pesquisa. Pesquisadores estão também olhando para longe do país, para os contextos mais pobres onde as pessoas que enfrentam carências de tratamentos e crises dos serviços de saúde aceitam dizer "sim". As paisagens de experimentação envolvem um tipo de toma lá dá cá onde as pessoas com necessidades médicas não atendidas aceitam dizer 'sim' para o movimento de capital global e de mercadorias científicas e médicas.

Ensaios clínicos envolvendo novos medicamentos são tipicamente divididos em quatro fases. $\mathrm{Na}$ fase 1, pesquisadores determinam a segurança e a dosagem de medicamentos experimentais e detectam os efeitos colaterais toxicológicos em um pequeno grupo (20-80) de voluntários sadios. Na fase 2 , 100 a 300 pessoas são recrutadas para avaliar a eficácia do medicamento e aprofundar análises sobre sua segurança. $\mathrm{Na}$ fase 3, o medicamento estudado é administrado a grandes grupos (1000-3000) de pessoas para confirmar sua 
eficácia, observar seus efeitos colaterais, compará-los a outros tratamentos e reunir dados sobre seu uso ótimo. Esses ensaios são frequentemente coordenados através de múltiplos centros de pesquisa que são localizados em diferentes partes do mundo. Estudos de fase 4, também conhecidos como vigilância pós-comercialização, são primariamente observacionais e não experimentais, em que companhias e agências reguladoras coletam dados sobre os riscos e benefícios do medicamento após sua entrada no mercado. A vigilância póscomercialização envolve milhões de pessoas, mas na prática permanece muito subdesenvolvida (Understanding..., 2007).

Em 2008, mais de 40\% dos gastos em pesquisa e desenvolvimento industrial ocorreram com ensaios clínicos. À medida que a pesquisa médica expande, a cadeia de empresas interessadas fica cada vez mais longa e mais descentralizada. Patrocinadores de experimentação farmacêutica dependem de redes de parceiros terceirizados para realizar sua pesquisa. A "indústria de ensaios clínicos" inclui uma multiplicidade de atores: de empresas para recrutar pacientes a locais de pesquisa; de organizações que administram locais de pesquisa a organizações para a pesquisa acadêmica; de companhias para explorar dados sobre pacientes a comitês de ética de instituições comerciais. É um negócio muito lucrativo - que representa aproximadamente um terço de todas as despesas para o desenvolvimento de novos medicamentos, e cujo crescimento está ultrapassando o crescimento da própria indústria farmacêutica. ${ }^{1}$ A maior parte das atividades terceirizadas ocorre nas fases 2 e 3 do desenvolvimento de medicamentos; essas fases são, de longe, as mais custosas em termos de tempo e dinheiro. Assim, um executivo da indústria de ensaios clínicos me disse: "Cerca de $60 \%$ de todas as despesas para o desenvolvimento de medicamentos são gastos com experiências nas fases dois e três. O dinheiro grosso está lá."

\section{Ensaios clínicos globais}

É difícil lançar mão de dados precisos sobre o número de ensaios clínicos ou o número de pessoas que participam neles, seja nos Estados Unidos ou no

1 Ver Parexel (2005, p. 35) e CenterWatch (2005, p. 162). Gastos com o desenvolvimento clínico terceirizado chegarão a US\$ 23 bilhões em 2008, o dobro do valor em 2003 (US\$ 11,2 bilhões). 
resto do mundo. Em parte, isso se deve ao fato de que a FDA não consegue identificar todos os ensaios clínicos em andamento ou seus centros (Office of the Inspector General, 2007). ${ }^{2}$ Em 2008, ClinicalTrials.gov, um serviço dos Institutos Nacionais de Saúde (National Institutes of Heal - NIH) que fornece dados atualizados para pessoas buscando localizar ensaios clínicos, publicou uma lista de 65.755 ensaios clínicos patrocinados por agências de fomento federais assim como por indústrias privadas. Estima-se que todo ano mais de 2,3 milhões de pessoas participam em ensaios clínicos nos Estados Unidos. Entre 2000 e 2005, a FDA fiscalizou menos de $1 \%$ dos 350 mil centros que o Setor de Inspeção Geral (Office of the Inspector General, 2007, p. 19) (responsável pela avaliação periódica da FDA) estima existirem atualmente no mundo. Enquanto isso, o campo global de atividades experimentais está florescendo - com uma envergadura e um alcance ainda pouco conhecidos.

$\mathrm{Na}$ primeira parte deste artigo, considero algumas das realidades regulatórias, econômicas e médicas subjacentes à terceirização e expatriação dos ensaios clínicos. O conceito de arbitragem dos "mercados" de ensaios clínicos, alimentados por regulamentações variáveis conforme as fronteiras nacionais e continentais, é central nesse raciocínio. A mobilidade é um elemento definidor da indústria de ensaios clínicos. Pretendo mostrar como, durante as últimas décadas, cresceu um campo de atividade experimental global - por vezes além da possibilidade de controle ou registro por regulações normativas. Na segunda parte deste artigo, considero as circunstâncias que permitiram a abertura de um campo global de experimentação. Mostro como a "experimentalização" da vida cotidiana nos Estados Unidos (em alguns setores) é intimamente ligada à globalização de experiências em outras partes do mundo. Nossa pauta inclui não só a descrição geral do capitalismo predatório e suas lacunas legais e regulatórias, mas também a investigação detalhada dos lugares concretos - e seus deslocamentos - nos quais a atividade de pesquisa cresce e se reestrutura. ${ }^{3}$

Ao examinar esse fenômeno, levo a sério o apelo do antropólogo Michael M. J. Fischer (2003, p. 35), recomendando que os antropólogos apreendam "os efeitos interativos dos [...] mecanismos escondidos das tecnologias (em

\footnotetext{
Sobre a cambiante geografia da pesquisa clínica, ver Office of Inspector General (2001).

3 A evasão corporativa das regulações é uma questão-chave, especialmente, nos novos estudos de campo da regulamentação. Para um panorama das pesquisas de campo sobre lei e nas ciências sociais, ver Greenhouse (2005).
} 
grande escala)", assim como a exortação de Bruno Latour (2006) de tornar as "coisas" (res) públicas. Nessa época global de mercados, ciência, tecnologia, crise ecológica e terrorismo, as pessoas são interconectadas, mas não são necessariamente "agregadas" por qualquer política ou nacionalidade comuns. Nossa tarefa, diz Latour, é fazer a política com os objetos certos - fazer uma montagem política a partir das variadas montagens nas quais já estamos envolvidos, interpretando essas montagens, e - se possível - identificando possibilidades políticas alternativas. Contrariamente, à medida que objetos e práticas de pesquisa nas ciências da vida são padronizados, devemos perguntar: quais são as práticas que os transformam em bens públicos despolitizados? Como a governança se configura enquanto proposta ética dentro dos variados ambientes globais por onde a tecnologia se move (Adams; Novotny; Leslie, 2008)? Qual o trabalho a ser realizado localmente para garantir responsabilidade com os pacientes e para reconectar os sujeitos de pesquisa a regimes de proteção? ${ }^{4}$

\section{De terceirizacão à experimentalidade}

Realizar ensaios clínicos ou não - onde e como - é uma decisão tanto econômica e política quanto científica. ${ }^{5}$ Essa economia política tem raízes profundas na medicina tropical e nos serviços coloniais de saúde, na experimentação em "nações-ilhas", na ciência de populações da Guerra Fria e no desenvolvimento internacional pós-Guerra Mundial na África, Ásia e América Latina. Da Comissão Walter Reed de Febre Amarela em Cuba e a erradicação experimental da malária em Cuba e nas Ilhas Maurício dos anos 1960 até os ensaios atuais ligados à vacina contra a AIDS contra a malária, a maioria dessas atividades envolveu patrocínio governamental, ativamente borrando as li-

\footnotetext{
4 Trabalhos antropológicos sobre a ética da biotecnologia e as novas tecnologias médicas têm aprofundado a análise de novas tecnologias biomédicas afetando padrões de organização cívica, médica e comercial (Biehl, 2007; Cohen, 1999; DelVecchio Good, 2001; Dumit, 2000; Lock, 2001; Petryna, 2002; Rapp, 1999; Scheper-Hughes, 2004). Novas tecnologias geram novos contextos de decisão quanto aos procedimentos justos; assim, além de definir instâncias de certeza moral, a ética também envolve um conjunto de táticas que podem ser geradoras de novas condições humanas e eventos (Fischer, 2003; Rabinow, 2003).

5 Ver a discussão de Harry Marks (1997, p. 13), que apresenta ensaios clínicos como instituições sociais.
} 
nhas demarcatórias entre pesquisa experimental e o fornecimento de serviços de saúde. ${ }^{6}$

A economia política de pesquisas de medicamentos também reflete práticas inerentes à indústria farmacêutica tal como evoluiu na América do Norte ao longo do século XX. Cito como exemplo a história das pesquisas entre minorias, entre os assim chamados pacientes cooperativos e as cobaias profissionais. Deve-se considerar também o poder que a indústria exerce sobre a produção de evidência e as políticas que regulamentam o uso de medicamentos, assim como a história duvidosa da pesquisa médica durante o início dos anos 1970 que deu origem ao campo atual da bioética. Por exemplo, no notório estudo Tuskegee sobre sífilis, que durou quatro décadas (1932-1972), o serviço público de saúde dos EUA negou tratamento-padrão para um grupo de 400 homens afro-americanos. Justificava que, conforme os princípios da "boa" ciência, tratava-se de um procedimento necessário para que os cientistas pudessem observar o curso natural da doença. Esse escândalo, entre outros que vieram à luz durante os anos 1960 e 1970, redefiniu o perfil de pessoas vulneráveis que exigiam proteção e levou a mudanças dramáticas na regulação de pesquisas conduzidas nos Estados Unidos.

Mais recentemente, pandemias devastadoras demonstraram que determinadas regulações nem sempre se mantêm em circunstâncias de crise. Por exemplo, em 1987, as regulações sobre investigações farmacêuticas foram revisadas para expandir o acesso de pacientes a tratamentos experimentais de AIDS. ${ }^{7}$ As regulações vigentes que definiam certos grupos de pacientes como

\footnotetext{
6 Ver os trabalhos de Packard (2007), Geissler et al. (2008) e Whyte et al. (2006), por exemplo. Sobre AIDS enquanto um domínio da expansão da medicina transnacional, ver Dodier, 2005. Pode-se dizer que um dos primeiros ensaios globais associados à "ciência da população" e com vínculos industriais explícitos iniciou em 1956, quando a Searle, uma empresa farmacêutica britânica, conduziu ensaios mundiais para a sua pílula contraceptiva Enovid (Marks, L., 2001). Estudos de campo iniciais da pílula foram realizados em Porto Rico, provavelmente por esse país estar fora da jurisdição das leis de Comstock. Essas leis (antiobscenidade) tornaram os testes de contraceptivos ilegais na maioria dos estados nos EUA (Marks, L., 2001, p. 265). Além disso, era uma ilha com uma população estável, excelente para o monitoramento da pesquisa; e abrigava um grande movimento de planejamento familiar com redes de clínicas de maternidade, excelentes para atraírem participantes de ensaios. Como Lara Marks (2001) mostra em seu importante livro, Sexual chemistry, a pesquisa do contraceptivo oral - o primeiro medicamento "estilo de vida" do século - juntou caridade e esforços internacionais de desenvolvimento com a expansão do mercado farmacêutico. Semelhantes padrões e parcerias público-privadas continuam hoje no contexto da filantropia frente à AIDS (Biehl, 2007).

7 E para outros pacientes com doenças graves sem terapias alternativas.
}

Horizontes Antropológicos, Porto Alegre, ano 17, n. 35, p. 127-160, jan./jun. 2011 
vulneráveis, os impedindo de servir como voluntários de ensaios experimentais para novas terapias, foram derrubadas por esses mesmos grupos. ${ }^{8}$ Esses pacientes julgaram que decidir sobre a aceitabilidade dos riscos assumidos era uma questão de direitos humanos. No entanto, esse episódio - em que pacientes redefiniram os termos permissíveis da experimentação - pode ser uma exceção na história da experimentação humana. É mais comum que os atores políticos, os interesses econômicos, as práticas científicas e a lei - e não os pacientes - renegociem a linha divisória entre o que é experimental e o que é não experimental (rotineiro, aceitável) (Marks, H., 2002), reformulando assim os termos pelos quais os direitos de sujeitos humanos são reconhecidos, protegidos ou violados.

À medida que eu rastreava suas práticas produtoras de evidência, meus interlocutores na indústria de ensaios clínicos detalhavam, por vezes com candor surpreendente, os desafios e as incertezas que comprometem a integridade de seus experimentos. Um executivo industrial me relatou que: "Considerando o custo do desenvolvimento de medicamentos e os riscos financeiros envolvidos, nem chegamos à fase de ensaio clínico a não ser que tenhamos certeza que o medicamento funciona. Não há nada pior do que 'matar' um medicamento tardiamente." Seu principal consultor científico questionou o mecanismo desse processo para a produção de evidência: "Hoje em dia, as companhias podem buscar e escolher as populações que melhor demonstram o benefício de determinado medicamento, assim como sua inocuidade." Buscar e escolher sujeitos que supostamente não receberam diagnóstico nem tratamento para a condição em estudo cria resultados eficientes, livres de "ruído" estatístico. Entretanto, meus informantes expressam sérias dúvidas quanto à possibilidade de generalizar esses dados. Consumidores, sem se darem conta, se tornam eles mesmos extensões experimentais desses "ensaios arquitetados" que podem trazer para o mercado produtos ineficazes ou inseguros.

Para propulsionar a competitividade global em torno da pesquisa com seres humanos, acordos sobre patentes e diretrizes unificadoras precisam existir, assegurando que a informação seja facilmente transferível. Juntos, esses acordos e diretrizes legitimam um fenômeno dinâmico e multifacetado que

8 Steven Epstein (1996) escreveu um trabalho eloquente sobre a mobilização social em torno da AIDS e os tratamentos de AIDS. 
eu chamo de experimentalidade. Em meu livro, When experiments travel (Petryna, 2009), eu discuto o funcionamento da indústria global de ensaios clínicos a partir da perspectiva de seus implementadores cotidianos e seus soldados rasos: as organizações de pesquisa terceirizadas $\left(\mathrm{OPTs}^{9}\right)$. Emergindo no início dos anos 1990, as OPTs são uma indústria especializada cujo foco é o recrutamento de sujeitos para pesquisa e desenvolvimento clínico. Seus clientes são companhias farmacêuticas que, ao selecionarem uma OPT, estão considerando o custo de um estudo, a sua qualidade e presteza. Qual é a aptidão específica, a expertise dessa indústria? Quais são os preceitos éticos e legais que governam suas atividades? Como ela responde à evolução de restrições regulatórias e científicas? E quais os canais que esse tipo de empreendimento, de pesquisa com sujeitos humanos, percorre para operar - e avançar?

Experimentalidade, eu aprendi, é um bicho complexo cujos movimentos transcendem qualquer separação artificial entre as condições controladas dos testes (o "laboratório") e o público (o "campo"). Em meu livro, escrevo sobre os desafios e os limites dessa utilização instrumental de seres humanos bem como depreendo a lógica, as brechas e lacunas nas estruturas existentes de regulação que legitimam internacionalmente um "trabalho mercantil impiedoso". ${ }^{10}$ Como, nesse contexto, conciliar imagens de circulação livre, arbitragem e lucros aparentemente sem risco com as formas reais de risco e responsabilidade de base?

Minha investigação em ensaios globais (principalmente relacionada a doenças crônicas e novas terapias genéticas) me levou à Europa Oriental e à América Latina e por uma cadeia altamente descentralizada de atividades empresariais. Essa cadeia está constituída por patrocinadores farmacêuticos, organizações de pesquisa terceirizadas, companhias de recrutamento de pacientes, consultores comerciais em ética de pesquisa, e centros independentes de pesquisa sediados em comunidades urbanas e suburbanas. A indústria de ensaios clínicos alega absorver cerca de metade dos gastos em desenvolvimento clínico. Curiosamente, enquanto o crescimento da indústria farmacêutica estagnou de certa forma - há cada vez menos medicamentos blockbuster (que vendem mais de US\$ 1 bilhão por ano) - o da indústria de ensaios clínicos disparou.

9 CROs no original: contract research organizations; no texto em português, é usada a sigla OPT (N. de T.).

10 "Cutthroat commodity work", no original, alude ainda ao caráter mortífero (N. de T.). 
Por que a indústria dos ensaios clínicos cresceu tanto nos últimos anos? Primeiro, o grande número de ensaios em curso; bem como o fato de existirem tantos produtos por aí que ainda precisam passar pelos testes clínicos. Segundo, para satisfazer as demandas regulatórias dos EUA, um maior número de pacientes, incluindo crianças, deve ser incluído nos ensaios clínicos para comprovar a segurança a longo prazo. Terceiro, algumas categorias de medicamentos $m e-$ too $^{11}$ estão se expandindo enquanto novos produtos são desenvolvidos. Com alterações farmacológicas mínimas, medicamentos me-too tomam como base e imitam medicamentos blockbuster para explorar mercados bem estabelecidos. A concorrência para a aprovação de medicamentos e para trazê-los ao mercado impulsiona a busca pelos sujeitos. Mudanças na base científica do desenvolvimento dos medicamentos também impactam o recrutamento de sujeitos. À medida que novas moléculas são descobertas, mais experiências vão sendo conduzidas (antes das fases formais dos testes em humanos) para a determinação de sua viabilidade clínica e de mercado. Finalmente, o contingente disponível de sujeitos humanos nos mercados farmacêuticos tradicionais do Ocidente está encolhendo. A "saturação de tratamentos" está tornando pessoas da América do Norte e da Europa Ocidental inadequadas para a testagem de medicamentos. Cientistas de OPTs me disseram que utilizamos drogas demais. Nossos corpos, já sendo o palco de muitas interações medicamentosas, são menos aptos a demonstrar a eficácia específica de um novo medicamento, diminuindo-se, assim, a validade estatística dos resultados dos testes. Paradoxalmente, o declínio na produtividade dos blockbuster exige ações compensatórias por OPTs que, em nome de experiências aprovadas pelas autoridades norte-americanas, procuram e suprem a demanda de inúmeros laboratórios no mundo inteiro.

Inicialmente, focalizei meu estudo na indústria norte-americana - como se desenvolveu e como vem atuando nos EUA; como executivos, administradores e cientistas definem seu trabalho e superam obstáculos operacionais e "exportam" ensaios clínicos. Os ambientes de pesquisa que as OPTs ajudam a construir em outros países são adaptáveis, móveis, e, em certa medida,

${ }^{11}$ Literalmente medicamentos "eu também" - medicamentos que a princípio não trazem novidade. Entretanto, a própria Agência Nacional de Vigilância Sanitária (Brasil) não se vale dessa classificação de medicamento, por sua própria complexidade narrada em http://www.anvisa.gov.br/medicamentos/ registro/metoos.htm (N. de T.).

Horizontes Antropológicos, Porto Alegre, ano 17, n. 35, p. 127-160, jan./jun. 2011 
parasitários. Eles se inserem em instituições públicas e, a qualquer momento, dependendo das políticas regulatórias e de cálculos de custo-benefício, podem se mudar para outro lugar. Elementos considerados no custo-benefício da localidade de ensaios incluem: perfil de doenças da população, índices de mortalidade, níveis de desemprego local, custo do ensaio por paciente e potencial de comercialização do medicamento a ser aprovado. As OPTs investigam o ambiente regulatório do país hospedeiro e consideram a abrangência dos serviços de saúde. Elas avaliam a eficácia dos comitês de ética locais, recrutam peritos, e preveem perspectivas e regulações sobre o uso de placebos, por exemplo.

Nessa abordagem custo-benefício a estratégia de minimizar o viés de seleção pelo uso de ensaios randomizados controlados (o suposto padrão-ouro para pesquisa) é implementada - mas também é contornada. Existe um viés de indução na projeção de protocolos e no recrutamento de populações "convenientes", como me disse um perito: "Na minha estratégia de recrutamento de sujeitos, posso me valer de critérios de inclusão tão seletivos que excluirão por desenho (engineer out) a possibilidade de eventos adversos serem detectados. Ou, posso demonstrar que meu medicamento é superior, ao aumentar por desenho (engineer up) um efeito colateral num medicamento concorrente [duplicando sua dosagem, por exemplo]... Esse é o grande jogo dos ensaios clínicos."

O particular viés desse processo visa garantir que, depois dos ensaios, não haverá mais possibilidade de detectar graves riscos. Iniciei essa pesquisa num momento de escândalo - quando revelações sobre efeitos adversos despontaram no mercado de medicamentos, tais como Vioxx (remédio antiartrítico) e outros, e quando muitos processos judiciais obrigaram as empresas a investirem em estratégias legais para combater litígios e restaurar a confiança dos consumidores. Para a indústria dos ensaios clínicos, a ética e a habilidade na consideração dos prejuízos estavam se tornando qualidades importantes de venda. Os cientistas que eu conheci raramente falavam de qualquer transgressão específica. Falavam, antes, de um modelo de lucros farmacêuticos competitivos que estava ameaçado pela diminuição dos retornos, a ineficácia e a produção sistemática de riscos.

Essa tendência à ineficácia e à perda de produção é característica do modelo comercial dominante para o desenvolvimento de medicamentos. Revelações de efeitos adversos de remédios lançados no mercado e os consequentes processos judiciais forçaram empresas a investirem em estratégias 
legais para combater litígios e restituir a confiança do mercado. Porém, remediar não é só uma questão legal, é também técnica. Um dos meus interlocutores sugeriu que o modelo operacional corrente de ensaios clínicos subestima rotineiramente os efeitos adversos ou riscos. Esse modelo opera conforme o que meu interlocutor chamou de "o paradigma da falha prevista". Ele me disse, por exemplo, que: "Em qualquer sistema industrial, se você gasta dez vezes mais consertando os dados do que em prevenção, vai seguir vivendo num ciclo contínuo de perdas. Para cada dólar gasto em uma investigação, dez dólares são gastos voltando e corrigindo os dados depois do fato."

Nessa abordagem de busca-e-conserta, problemas de segurança são detectados depois do fato. Infelizmente, de acordo com um advogado americano a serviço de uma pequena empresa farmacêutica, alguém tem de sofrer danos durante o ensaio clínico para identificar quem é o responsável. Enquanto isso, patrocinadores corporativos espremem o que podem de um paradigma tecnicamente gasto, pautando produtos farmacêuticos como um evidente benefício social. Em sua modalidade expatriada, a indústria farmacêutica exporta o paradigma da falha prevista, afetando toda uma gama de escalas e instituições (médicas, estatais, jurídicas e regulatórias). E, como eu saliento alhures, precisamos de novas formas de mobilização política para reformar essa realidade de risco (Petryna, 2011).

Já que uma das minhas preocupações era a integridade científica, no livro When experiments travel mapeei os complexos contextos de captação de informações e cálculos de riscos que evoluíram com a expatriação de ensaios clínicos (para a Polônia, por exemplo). Como são modificadas as normas éticas, como elas variam de um lugar para outro, como a informação é estrategicamente manufaturada e, por vezes, estrategicamente censurada? Por que o debate sobre a mercantilização de pacientes e de conhecimentos raramente acontece? Quais são as variáveis institucionais que permitem à experimentalidade florescer e (cedo ou tarde) deteriorar? Além dos gestores e monitores de ensaios, entrevistei cientistas de universidades públicas, e também considerei os efeitos das pesquisas clínicas financiadas por empresas privadas em sistemas frágeis de saúde pública (no Brasil, por exemplo). A análise comparativa - incluindo diversas regiões e diversos sistemas de responsabilidade e lei - é necessária para revelar as "falhas e lacunas", assim como as "enormes deficiências" da informação pública que impedem a compreensão do fenômeno total (Malinowski, 1961, p. 13). É a partir dessas "falhas e lacunas" que 
podemos acessar os riscos e impactos médicos e sociais da experimentalidade global e também esboçar formas alternativas, sociais e científicas, de responsabilização que poderiam ser adequadas às necessidades da saúde pública.

\section{Variabilidade ética}

A indústria de ensaios clínicos permite um vislumbre da "arbitragem massiva" que "é realmente a definição de globalização" (Garnier, 2005). Burocratas, coletores de evidência, e empresários estão todos enredados no que um consultor para a indústria me descreveu como "um trabalho comercial impiedoso". A expatriação da indústria, de acordo com o diretor de uma empresa líder em farmacêutica, reflete o "desafio real da globalização [... que] é obviamente o de permitir a você considerar a transformação da sua empresa. Em outras palavras, você pode desagregar todos os principais processos da firma serviços financeiros, produção, pesquisa e desenvolvimento, e reconstruí-los" em outro local. Você pode "ter acesso a estoques de recursos de baixo custo, bem como a valiosos trabalhadores capacitados, onde quer que eles possam ser encontrados" (Garnier, 2005). Essa perspectiva executiva de expatriação em que o desenvolvimento do medicamento é comparado à produção automobilística ou a qualquer outro processo industrial - é animada pela arbitragem. A arbitragem é um investimento calculado para tirar o máximo benefício da eventual mudança de preços; é uma forma de lucro sem riscos. ${ }^{12}$ Desmantelar processos industriais para reconstruí-los em outras localidades permite às empresas "aproveitar completamente a enorme arbitragem que é a real definição da globalização - arbitragem no custo do trabalho, no custo financeiro, mas também na reserva de empregados capacitados e seus obstáculos regulatórios e administrativos" (Garnier, 2005). Por exemplo, a GlaxoSmithKline anunciou recentemente seu objetivo de expatriar um terço de seus ensaios clínicos para países mais baratos como a Índia e a Polônia. Como explicou seu diretor: "Cada ano, lidamos, no total, com cerca de 60 mil pacientes em ensaios clínicos - então, se você mudar, digamos, 20 mil daqueles pacientes para a Índia, você economiza mais de US\$10 mil por pessoa. Trata-se de uma economia de US\$ 200 milhões só aí." (It's a perfect storm..., 2004).

${ }^{12}$ Ver http://www.investopedia.com. 
A variabilidade que a arbitragem explora é radicalmente distinta do relativismo cultural de uma época anterior. No campo da antropologia médica, a confiança na cultura para explicar diferenças em práticas globais de saúde tem sido um projeto central há décadas. ${ }^{13} \mathrm{O}$ conhecimento de diferenças culturais enquanto traduzidas na arena dos cuidados com a saúde tende a enfocar diferenças morais "insolúveis" entre grupos ocidentais e não ocidentais. No debate entre ética imperialista versus relativismo (Macklin, 1999), antropólogos trabalhando nas arenas dos cuidados com a saúde e noutros campos têm sido acusados de cegamente defenderem tradições locais, tornando-os suscetíveis às "consequências morais e intelectuais comumente derivadas do relativismo - subjetivismo, niilismo, incoerência, maquiavelismo, idiotia ética, cegueira estética, e assim por diante" (Geertz, 2000, p. 42). ${ }^{14}$

$\mathrm{Na}$ medida em que o mundo se torna uma série de locais para a produção de dados e laboratórios interconectados, a variabilidade ética torna-se um elemento-chave do desenvolvimento e dos testes de farmacêuticos. Para consolidar um modelo custo-benefício para critérios éticos na pesquisa com humanos, é preciso levar em consideração, como axioma e como base, as especificidades do contexto local e da experiência vivida. Ao definir novas fronteiras de

13 Aqui, a variabilidade não se destina a evocar a noção de relativismo cultural, embora a variabilidade tenha sido usada nesse sentido (Christakis, 1992).

${ }^{14}$ Antropólogos da saúde recentemente têm sugerido que enfocar a diferença cultural e moral em cuidados de saúde se tornou perigoso para as próprias pessoas e práticas que os antropólogos procuraram explicar, especialmente em contextos de epidemias massivas e debates sobre acesso a tratamentos. Como o antropólogo e médico Paul Farmer (2002) e outros apontam, a cultura tem sido usada para explicar "por que" os pobres são de alguma forma menos responsáveis em relação a regimes de tratamento. O desenvolvimento assustadoramente lento do mercado de medicamentos anti-HIV na África, por exemplo, tem sido atribuído aos comportamentos econômicos e médicos "não confiáveis" dos portadores de HIV desesperadamente pobres daquele continente. Tais características aumentariam o risco do investimento e justificariam o acesso limitado a drogas baratas. O médico e antropólogo Jim Yong Kim (1999) expôs a forma pela qual suposições moralistas no planejamento de saúde podem engendrar a desigualdade, justificando algumas intervenções e desautorizando outras. Outros antropólogos da saúde têm mostrado como as trajetórias locais de pandemias são influenciadas pela lógica das escolhas e políticas internacionais. Esses trabalhos estudam como diferenças na organização de instituições autorizadas a lidar com problemas de saúde (burocracias estatais, serviços de assistência social, seguradoras, instalações médicas e organizações religiosas e humanitárias) resultam em programas e em políticas diversas. Estes não apenas variam muito na forma e no conteúdo, eles também podem produzir diferentes trajetórias de saúde e de doença, influenciando o resultado final de ambos (Petryna; Kleinman, 2006). São trabalhos que se movem para além da ênfase na diferença, na arena da saúde, e indicam os tipos de trabalho empírico que são requeridos para dirigirem-se às realidades morais, éticas e culturais dos emergentes mercados globais das drogas.

Horizontes Antropológicos, Porto Alegre, ano 17, n. 35, p. 127-160, jan./jun. 2011 
pesquisa e ao comparar seus diferentes níveis "locais" de cuidados e demandas, essa variabilidade ética evita padrões internacionais de cuidado e evolui como tática comercial na mobilização de sujeitos humanos de pesquisa e no deslocamento de ensaios pelo mundo (Petryna, 2005). Deliberações sobre a ética da pesquisa competem com e podem inclusive ser eclipsadas pela ética mercantil de cientistas e reguladores industriais. "Existem tantos lugares onde podemos trabalhar que conseguimos contornar o assunto [o debate ético] completamente", disse-me um fundador de uma OPT.

Para ilustrar a variabilidade ética, um empresário industrial que eu chamarei de Evan descreveu o destino de um estudo que ele disse ser "impossível de conduzir" nos Estados Unidos. O protocolo de pesquisa envolvia administrar regularmente em crianças injeções de um agente usado para produzir imagens em exames de câncer. O produto foi aprovado para o uso em adultos, e o fabricante queria ter a aprovação para o uso em crianças. A FDA exigiu que o fabricante conduzisse um ensaio em crianças saudáveis (de seis meses a dois anos de idade) para a determinação da dosagem apropriada. "Mas qual pai nos EUA colocaria o seu próprio filho saudável num ensaio com um produto fabricado para produzir imagens em exames de câncer?" ele me perguntou, retoricamente. "Algumas vezes", ele disse, "a FDA tem demandas um pouco desconectadas daquilo que as comissões éticas institucionais estão dispostas a aceitar." Ele me disse que pesquisadores americanos rejeitaram o estudo justamente por acreditarem que envolvia um produto "que poderia ser prejudicial à saúde da criança". Evan mandou então o protocolo aos seus colegas russos. Eles também o rejeitaram. "Se o protocolo é rejeitado na Rússia, para onde ele vai em seguida?" eu queria saber. Ele disse que não sabia. Suspeitava que o produto seguiria sendo usado independentemente dos protocolos - isto é, prescrito para o uso infantil sem jamais ser sistematicamente estudado em crianças.

Evan contava com o fato de que riscos associados a ensaios clínicos são medidos diferentemente dependendo da localidade e, como o seu exemplo mostra, as normas regulatórias estadunidenses antecipam uma geografia de pesquisa clínica desigual para o seu cumprimento. A FDA encoraja companhias farmacêuticas a estudar o efeito de seus produtos em crianças. No Ato de Modernização da FDA, existe, por exemplo, um Incentivo a Estudos Pediátricos: em alguns casos, estende-se a exclusividade de patente por seis meses além do prazo normal quando o patrocinador consegue testar a droga 
em populações pediátricas. Num certo sentido, o esforço da FDA para gerar tal informação pode ser visto como louvável. Mas de quem serão as crianças testadas? A agência ainda deve investigar sistematicamente como seus incentivos e suas normas probatórias são aplicados de fato no cenário global. Aqui, basta dizer que, considerando os desafios e as oportunidades colocados pela regulamentação dos EUA, a localização se torna uma decisão econômica chave para o benefício da empresa.

As OPTs acham os países do Leste Europeu atraentes já que, por causa da demanda frustrada por cuidados especializados, o recrutamento de pacientes costuma ser rápido. Também nessa região, os altos índices de alfabetização apontam para um consentimento informado que "significa mais", minimizando assim potenciais problemas com auditores. As OPTs competem por "quem consegue recrutar pacientes, com quem eu posso me aliar para que, quando eu estou lidando com um patrocinador, eu possa lhe dizer 'amanhã e manhã, eu posso fornecer 500 pacientes de câncer para você'". O Leste Europeu também é conhecido pela suposta ausência generalizada de tratamento, tanto para doenças comuns quanto para incomuns. Digo "suposta" porque as pessoas em países de média e baixa renda, tal como as pessoas em países afluentes, podem estar consumindo diversos medicamentos ou fazendo tratamentos, não raro assistematicamente. Esse fato antropológico não impediu as empresas de identificarem lugares precisos onde creem poder encontrar os indivíduos chamados "virgens de tratamento" (isto é, aqueles que não foram diagnosticados ou tratados para a condição em estudo) - em uma região ou num hospital mais pobres, por exemplo. Como um pesquisador me disse, estas populações "oferecem a oportunidade de minimizar o número de variáveis afetando os resultados e de maximizar a demonstração da eficácia da droga".

Como frisei acima, os ambientes para ensaios clínicos que as OPTs ajudam a produzir são adaptáveis, móveis e, até certo ponto, parasitários. Eles se inserem em conflitos sobre reformas de mercado e o papel do Estado e das instituições públicas em sociedades locais. A qualquer momento podem mudar para outro lugar. Gestores nacionais, especializados em saúde pública e em regulação da indústria têm grande interesse em atrair e manter em seus países investimentos para ensaios clínicos. Esses especialistas desempenham um papel-chave na modelagem de entendimentos públicos quanto a ensaios clínicos - seu benefício para pacientes e, de forma mais abrangente, para a o sistema de saúde pública. Mas esses empreendimentos nem sempre fornecem 
os resultados mais seguros e relevantes para aliviar o sofrimento provocado pela doença. Estimativas calcadas em contextos específicos informam as políticas de expatriação e os aspectos do modelo operacional para ensaios clínicos. Porém, junto com os centros de pesquisa, exportam-se também técnicas fracassadas para prever a segurança do medicamento.

\section{Sujeitos para o resgate da pesquisa}

A rotinização da experimentalidade entre algumas populações nos EUA e a globalização dos ensaios clínicos estão intimamente vinculadas. Nos anos 1970 e 1980, medicamentos foram amplamente testados em populações civis não institucionalizadas nos EUA e na Europa Oriental, no contexto da pesquisa acadêmica médica. Embora, como assinalado, o uso de presos para pesquisa não terapêutica nos Estados Unidos foi banido em 1980, a continuidade desse tipo de pesquisa tem fortes defensores. Dr. Lou Lasagna, cofundador do Tufts Center for the Study of Drug Development (Centro para Estudo do Desenvolvimento de Medicamentos), contestou o fechamento da infraestrutura de testagem nas prisões, pois diminuía a capacidade de pesquisadores testarem reações adversas a determinados remédios. O uso de prisioneiros, especialmente os reincidentes, tornou possíveis os estudos sobre a segurança de tratamentos a longo prazo. Referindo-se ao fechamento de um centro de pesquisa em dependência química ligado a uma prisão no Kentucky, Lasagna escreveu que "sem recorrer a tal instituição, este trabalho provavelmente não será empreendido em qualquer outro lugar, e o público doente se tornará o sujeito involuntário de pesquisa (não consentida) do futuro" (Lasagna, 1977, p. 2351).

No início dos anos 1990, o grosso dos ensaios clínicos ainda transcorria em nações ocidentais. Com a "explosão das pipelines de medicamentos" e a demanda exagerada por centros de investigação, as empresas farmacêuticas dos EUA e as OPTs começaram a sondar e até mesmo preferir recorrer a clínicas médicas e centros de atenção primária em saúde em lugar dos tradicionais centros clínicos acadêmicos. O número de equipes médicas e médicos de atenção básica procurando integrar suas práticas ao mercado de ensaios clínicos aumentou continuamente, e depois caiu na última década. O interesse inicial se explica, em parte, como uma resposta à redução de verbas para a área da saúde e mudanças na estrutura de pagamentos dos planos de saúde; médicos 
viram nos ensaios clínicos uma fonte adicional de renda. Mas os benefícios frequentemente não se materializaram, devido aos muitos "gastos embutidos" e não compensados associados à inicialização do estudo, ao cumprimento das normas regulamentárias, e ao relatar e gerenciar eventos adversos (Parexel, 2005, p. 125). Essa economia também informa o intratável problema do que meus informantes de OPTs chamam de locais flutuantes (floater sites) empreendimentos efêmeros que prometem muitos pacientes, têm poucos contratos e não estão particularmente comprometidos, ou empenhados com o pleno cumprimento das regulações. Eles fazem o seu dinheiro e logo desaparecem da cadeia alimentar dos ensaios clínicos. Sua existência diminui a lucratividade da pesquisa clínica nos Estados Unidos. ${ }^{15}$

Consideremos a seguinte história que um pesquisador industrial me contou. Um fabricante tinha abordado sua empresa para testar um produto (atualmente retirado do mercado) para usos adicionais. O protocolo tinha sido projetado para mostrar que o medicamento poderia tratar, entre outras coisas, infecções provocadas por apêndices rompidos. O pesquisador explicou por que a sua OPT perdeu e outra venceu o contrato.

Ao passo que nós procuramos locais acadêmicos consagrados para o recrutamento de pacientes, eles foram ao sul dos Estados Unidos, para uma série de instituições onde pudessem encontrar seus sujeitos para o ensaio. Indo a uma cadeia hospitalar no sudoeste do país onde se trata principalmente hispânicos que normalmente têm pouco ou nenhum seguro de saúde, essa OPT conseguiu recrutar muito mais que nós.

A realidade das pesquisas de "resgate" acrescenta uma nova camada de complexidade às formas pelas quais tendências domésticas informam o movimento global da pesquisa patrocinada pela indústria. O termo "resgate" se aplica a um estudo que inicia numa localidade, mas por conta da escassez do recrutamento é transferido para outro lugar em pleno processo do estudo. Alguns dos ensaios que foram inicialmente desenvolvidos na Europa Ocidental, por exemplo, foram mudados para países do Leste Europeu (que foram considerados "países de resgate" na primeira metade dos anos 1990).

15 Existe atualmente um movimento para que se licenciem esses locais, tal como se faz com clínicas de odontologia, mas a indústria resiste ferozmente. 
O termo também pode se aplicar a um estudo que ocorre quando o ciclo de vida de uma nova droga é subitamente interrompido. Isso requer recrutamento rápido de pacientes e uma montagem rápida de estrutura. Estudos de resgate desse tipo podem ser resultado de falhas imprevistas do produto (por exemplo, efeitos colaterais adversos). Ambos os modos de resgate nos revelam uma porção significativa de pesquisa clínica que foi "globalizada".

O olhar etnográfico dirigido às práticas rotineiras da pesquisa com sujeitos humanos aponta para a questão mais abrangente de como pressões comerciais mudam as próprias formas da experimentação científica; e como danos sistêmicos em potencial são produzidos nas práticas do dia a dia que podem iludir as orientações dos protocolos escritos. Mecanismos de auditoria não se expandiram para acompanhar a proliferação dos locais flutuantes; existem, portanto, preocupações quanto à confiabilidade da informação produzida ali. Entretanto, são esses fatores palpáveis que empurram a experimentalidade para outros países - seja na busca por mais locais flutuantes, seja na tentativa de escapar das dificuldades econômicas que o sistema impõe nos Estados Unidos. Países como Polônia, por exemplo, oferecem seus serviços de pesquisa como uma alternativa mais confiável aos locais flutuantes. Mas, para seu desânimo, os pesquisadores poloneses não conseguem se livrar de sua reputação e atratividade enquanto pesquisadores de resgate na economia experimental global.

\section{A ciência das falhas esperadas}

Observei as atividades de administradores e cientistas de uma organização de pesquisa terceirizadas na sua filial na Europa Centro-Oriental, para entender como os centros de ensaio clínico são operacionalizados. Primeiro encontrei o médico Jan Mazur quando ele visitou as instalações da organização Tem/po. Mazur lidera essa expansão de OPTs através do Leste Europeu. Ele veio falar para os vendedores da Tem/po sobre a alta produtividade de dados nessa região. Durante a sua apresentação, Mazur providenciou dados sobre os terríveis indicadores de saúde da Polônia e seus financeiramente debilitados sistemas universal de saúde e de seguro-saúde. Ele justapôs esses dados a informações sobre a alta qualidade da pesquisa clínica e à adaptação polonesa a padrões internacionais. A mensagem direcionada a potenciais clientes era clara: não haverá dificuldade em recrutar pacientes e os dados 
serão confiáveis. Mazur também transmitiu histórias de sucesso no recrutamento, todas elas envolvendo estudos de resgate.

Quando cheguei à Polônia, porém, as histórias de sucesso de Mazur se mostraram um pouco mais complicadas. Uma dessas histórias envolvia um estudo sobre um medicamento para diabéticos. Segundo critérios de inclusão, o estudo exigia pacientes com níveis "muito altos" de açúcar no sangue que nunca tinham sido tratados. Na Europa Ocidental, o recrutamento para o estudo tinha sido inadequado. E na Polônia, Mazur expressou ansiedade sobre as pressões no recrutamento de pacientes "perigosamente doentes [...] Se você foi recentemente diagnosticado", ele disse, "é impossível você ter níveis tão elevados de açúcar no sangue!" Ele estava se referindo a contextos médicos "normais", onde o diabetes seria naturalmente diagnosticado e tratado a partir de níveis muito menores de açúcar no sangue. Ele deixou entender que tudo dependia do momento do diagnóstico. Havia espaço para manobras e aí é que repousam os potenciais abusos.

Mazur me explicou que o medicamento estudado "não era muito diferente" daquele que já estava no mercado, mas os pacientes estavam escolhidos de modo a tornarem pequenas diferenças terapêuticas mais óbvias (era uma droga me-too, e o nível de aprimoramento farmacológico em relação ao medicamento já existente no mercado, me falaram, era negligenciável). Esses pacientes selecionados com índices anormais e perigosamente altos de açúcar no sangue eram "pacientes não-existentes" que Mazur tinha que "produzir". Conseguiu modificar ligeiramente o critério de inclusão para poder recrutar pacientes cujos níveis de açúcar no sangue não eram tão elevados. Ao mesmo tempo, Mazur ensinou seus monitores a exercer extrema vigilância para evitar que investigadores locais, suscetíveis a pressões (ou incentivos), recrutassem "pacientes perigosamente doentes". Médicos locais tinham muita oportunidade para manipular seus diagnósticos. Ele chamou essas situações de pesquisa de "complicadas": "Protocolos complicados estão emergindo", enfatizou Mazur.

As situações carregadas de riscos das quais Mazur falou diziam respeito a estudos de resgate para medicamentos me-too. Estes não eram ensaios de tratamentos genéticos ou de intervenção cardíaca - ensaios que poderíamos normalmente associar com uma maior complexidade - mas ensaios para medicamentos que constituem a maioria dos atualmente aprovados pela FDA (Angell, 2006). Alguns experimentos, ele me disse, "são simplesmente impraticáveis nas condições dadas". 
Paradigmas de falha esperada afetam todas as partes da cadeia de ensaios clínicos, com diversas consequências legais, éticas e médicas para aqueles envolvidos. O patrocinador do ensaio provavelmente vai se preocupar menos (de início, ao menos) com um protocolo perigoso ou mal projetado. Inclusive, poderia levar o protocolo perigoso para outra OPT ou para outro país - se a empresa de Mazur decidisse rejeitá-lo.

Um sistema de pesquisa clínica dramaticamente expandido redefine segmentos da população como objetos de governo e os termos da participação pública em pesquisa biomédica do setor privado. Mas em que termos? Em seu estudo basilar Inclusion, Steven Epstein (2007) investiga reformadores médicos dos EUA que exercem pressões para incluir grupos sub-representados (conforme sexo e gênero, raça e etnia, e idade) em pesquisa científica. Durante anos, reformadores médicos questionaram a possibilidade de generalizar informações biomédicas, alegando que a diversidade da vulnerabilidade a doenças e dos resultados do tratamento é reflexo da variabilidade humana. Epstein (2007, p. 281) mostra que a institucionalização do paradigma norte-americano de inclusão e diferença conduziu, entre outras coisas, a uma reificação biológica de categorias de identidade, afastando as atenções das desigualdades que estão assentadas não na biologia, mas na sociedade.

Enquanto os Institutos Nacionais de Saúde (National Institutes of Health) estadunidenses exigem a diversidade em ensaios clínicos para maximizar seu potencial generalizador, não fica tão claro como essa pressão para inclusão biossocial - baseada no recrutamento de populações de sujeitos humanos "medicamente distinguíveis" - tem sido interpretada pela indústria ou como ela é recebida na pesquisa expatriada. Se o exemplo polonês descrito acima for tomado como indicativo, uma retórica da eficácia (isto é, a capacidade de identificar e às vezes criar amostras epidemiologicamente convenientes conforme critérios regulatórios particulares) triunfa sobre uma retórica da diversidade. Através de projetos protocolares e critérios de seleção de sujeitos, a indústria promove dispositivos científicos de ensaio que, nas palavras de Epstein (2007, p. 281), "podem enterrar as diferenças potencialmente detectáveis entre subgrupos".

Mais do que ensaios precisos, randomizados e controlados em que pessoas estão livres para participarem conforme suas inclinações, o que está acontecendo é experimentalidade. Nela, podemos nos tornar extensões experimentais involuntárias de ensaios arquitetados para pôr no mercado medicamentos 
potencialmente ineficazes e inseguros. Impor estritas diretivas para o recrutamento conforme gênero ou raça, por exemplo, se torna menos importante. Quando a racionalidade científica dos protocolos está em desacordo com a realidade clínica, os danos, após o fato, são difíceis de detectar. O poder do indivíduo - de avaliar o risco e de exercer seus direitos legais - se torna limitado diante da invisibilidade dos danos. A frequência dos riscos comuns se distribui diferentemente em populações diversas - não somente para aquelas a quem os ensaios clínicos servem de terapia experimental, mas também para os usuários finais dos novos medicamentos.

$\mathrm{Na}$ medida em que esforços para a elucidação dos danos farmacêuticos estão a caminho - através de processos coletivos por danos, editores de publicações médicas, e legisladores exigindo que os resultados dos ensaios sejam guardados em bancos públicos de dados - uma nova economia global da experimentação se forma sem um olhar adequado a esses diferentes tipos de riscos. Comecei a pensar na experimentalidade - sua suspensão de conhecimentos e sua distribuição não mapeável do risco - no contexto de meu trabalho antropológico anterior sobre os resultados do desastre nuclear em Chernobyl. Life exposed (Petryna, 2002) mostrava como uma catástrofe de escala inconcebível, difícil de mapear, e "saturada" se tornava administrável através de uma dinâmica de "não conhecimento" ou ignorância. Protelando a divulgação pública do desastre, suprimindo informações sobre mortes, forjando parâmetros limitados para riscos biológicos e filtrando legalmente reclamações por danos, políticos estatais exacerbaram problemas de saúde pública que pretendiam resolver, gerando novos problemas.

O tipo de experimentação desencadeada nesse desastre excedia às capacidades logísticas de qualquer agência ou estado para gerar uma forma de controle. Os avanços e recuos de conhecimento sobre ela dependiam, por sua vez, de momentos-chave de mudança política e econômica e de negociações que, no final, deixaram cidadãos com pouca margem de manobra (além da sua própria "ignorância") para ações compensatórias junto ao Estado. Clínicas de pesquisa e organizações não governamentais mediavam uma economia informal da doença, lidando com uma demanda massiva (diante de um acesso seletivo) por uma forma de previdência social baseada em critérios científicos e legais que identificam danos e promovem compensações, um fenômeno que chamei de cidadania biológica. 
A cidadania biológica tornou-se o domínio médico-político-legal em uma era tecnológica na Ucrânia pós-socialista. Um domínio em que, espirais descendentes de saúde se aceleravam para alguns e a proteção era seletivamente promovida para outros, e onde as injustiças de tais destinos eram, simultaneamente, mais conhecidas e contestadas. Não se tratava de uma identidade compartilhada produzida por uma nova infraestrutura, mas da normalização do risco. Na prática, cidadania biológica também implicava o aumento de vulnerabilidade para aqueles que não conseguem se adequar aos critérios estabelecidos.

Com o crescente número de ensaios clínicos, as características dos cidadãos se apresentam como recursos não apenas para o Estado, mas também para o mercado. A própria ideia de cidadania vinculada à vera sobrevivência faz proliferar uma nova figura médico-social - um paciente cidadão que perdeu a confiança nas formas estatais de proteção e que está procurando por outras formas de proteção, mesmo que temporárias. Ataques à saúde engendram um contexto em que o cidadão biológico, de forma cada vez mais frequente, reivindica recursos biomédicos (também na forma de acesso a ensaios clínicos e tratamentos experimentais). Mas o que está sendo obliterado pela arquitetura desse sistema experimental global tal como está sendo atualmente promovido? Será que os regimes de ética, regulação e lei, em diversos lugares, estão reengendrando o que constitui cidadania biológica?

Durante minha pesquisa de campo, por óbvio que possa parecer, sempre me espantava com a capacidade do setor privado de ignorar as demandas de sistemas locais de saúde. Dr. Mazur demonstra isso na frase memorável: "Não vejo pacientes. Vejo dados." Os contextos de carência e desigualdade inerentes a indicadores diferentes de vida e morte são completamente omitidos, higienizados. Eles são substituídos por um cálculo de custo-benefício do contexto local, constituindo a base sobre a qual um cientista consolida o seu empreendimento. A experimentalidade se apoia na noção de benefício social que o ensaio clínico supostamente, eclipsando outras formas de imaginar modos de inovação médico-científica em que a questão do acesso e da justiça é central, não periférica. Perdidas em todas as histórias de sucesso, encontramos questões simples como: qual o valor que esse paciente traz a essa empresa industrial globalizada? A expatriação da pesquisa acontece num momento em que a filantropia farmacêutica reina nas mais altas esferas acadêmicas e da saúde global, quando mercados farmacêuticos e "mercados de virtude cívica" 
operam paralelamente e convergem. O diretor do orçamento global de uma grande indústria farmacêutica se gabava da maneira em que sua empresa tinha cooptado o discurso sobre acesso à justiça e direitos humanos na região sul do globo. Seu slogan era: "Você não precisa dos ativistas, apenas compre nossos medicamentos."

\section{Sujeitos de pesquisa do futuro}

$\mathrm{Na}$ medida em que experimentos redefinem a linha entre, por um lado, bens comerciais frequentemente inacessíveis e, por outro, o direito à saúde, como é que algo tão amorfo e pessoal como o cuidado e a assistência ganhem forma em regimes tecnocráticos de medicina global? Na Polônia, no Brasil, e em número cada vez maior de lugares, ensaios clínicos são rotineiramente integrados a sistemas locais de saúde e alardeados como benefícios à saúde pública (acesso, ainda que limitado a tratamentos "de ponta"). Contudo, experimentos também servem como caminho poderoso para a introdução de novos medicamentos no mercado. As instituições públicas são obrigadas a lidar com novos mercados terapêuticos e as demandas populares por novos tratamentos médicos. A constituição progressista do Brasil, nascida durante a transição da ditadura militar para um regime democrático, garante o direito universal aos cuidados com a saúde. Cidadãos estão reivindicando novos tratamentos com base nesse direito. Grupos de pacientes estão modelando seus esforços legais, tomando inspiração na mobilização exitosa pelo tratamento universal de AIDS (Biehl, 2007). Essa combinação de medicina mercantil, lei e direitos humanos pode levar a um reducionismo conceitual e prático dos cuidados com a saúde como sendo equivalente ao fornecimento de medicamentos. A "farmaceuticalização da saúde pública" ou a "mudança progressiva no conceito de saúde pública, da prevenção e do cuidado clínico para serviços comunitários de cuidado e medicação" (Biehl, 2006, p. 223) levanta questões vitais sobre prioridades em saúde pública e seus financiamentos, e o papel da equidade no direito humano à saúde.

Cidadãos brasileiros também estão indo ao judiciário para obter medicações prescritas e que, muitas vezes, deveriam estar disponíveis através de programas governamentais. Por esse processo controverso relativamente novo, acontece uma "judicialização do direito à saúde" no contexto de um sistema 
de saúde pública disfuncional e descentralizado (Biehl et al., 2009). Com uma população de cerca de 190 milhões de pessoas, o Brasil tem um dos mercados farmacêuticos mais acelerados do mundo, rendendo mais de US\$ 17 bilhões em 2009. Medicamentos pagos pelo governo constituem um fabuloso mercado. A demanda por acesso à medicina em combinação com a fraca supervisão regulatória e limitado monitoramento de tecnologias médicas tem gerado um ambiente favorável ao crescimento do mercado farmacêutico. Ao mesmo tempo, pacientes pobres e suas famílias não estão esperando (como querem os economistas) que as tecnologias, novas e caras, venham filtradas de cima para baixo, chegando eventualmente a eles. Eles estão se valendo da defensoria pública e dos mecanismos de um judiciário atencioso para obter pleno acesso às medicações hoje. À luz da judicialização brasileira, o acesso ao tratamento princípio básico da saúde global contemporânea - traz seus próprios desafios legais-nacionais e médico-éticos (Biehl et al., 2009).

Em 2007, tomei conhecimento de um caso em que tanto os sujeitos de ensaios quanto os pesquisadores foram confrontados com um impasse ético incontornável. Os médicos de um hospital universitário estavam testando uma nova terapia para uma rara síndrome hereditária. Foram recrutados pacientes em estágios avançados da doença que nunca tinham recebido qualquer tratamento, conforme as exigências do protocolo de estudos. O diretor do serviço acolhia o ensaio por causa dos recursos que viriam junto. Sem o conhecimento dos seus colegas, concordou com a demanda da empresa biotecnológica que se reservava o direito de interromper a medicação a qualquer momento - essa condição constava nos formulários escritos de consentimento que os pacientes assinavam. Contudo, informalmente, a empresa se dispôs a providenciar a medicação por dois anos, e, de fato, continuou a fazê-lo por um terceiro ano. A medicação funcionou bem. Mas, sem pré-aviso, a empresa terminou o estudo. Em conversa com os médicos do hospital, um representante da empresa sugeriu que o governo brasileiro tinha sido lento na aprovação do medicamento para entrada no mercado. Advogados da empresa tinham contatado os pacientes, os encorajando a formar um grupo ativista que poderia pressionar o governo para pagar o preço do medicamento (por um custo de até US\$200 mil anuais por paciente). Esse esforço fracassou. Mais tarde fiquei sabendo que a empresa que conduziu o ensaio foi vendida. Seja qual for o motivo do término do ensaio, os médicos não tinham acesso a nenhum recurso institucio- 
nal. O tratamento cessou. Dentro de quatro anos, seus pacientes na fase mais avançada da doença provavelmente estariam mortos.

Inácio Santos, um senhor de meia-idade, me disse que tinha sintomas da doença em questão desde a adolescência. Veio do interior para participar do ensaio - mas agora, depois da abrupta interrupção, estava tentando entender seu novo desafio clínico e legal de como ter acesso à medicação. "A maioria das pessoas com a doença, na minha idade", ele disse, "já morreram ou se mataram." Perguntei se o tratamento tinha prolongado sua vida. "Sobrevivi", ele respondeu, "escolhi participar. Eu poderia ter optado por não fazer nada, e talvez eu não estivesse conversando contigo hoje. Mas não tenho nenhuma forma de saber o efeito real do estudo." Pesquisadores, conforme o protocolo, tinham se comprometido a não dizer para os pacientes se valia a pena ou não simplesmente ir para casa.

Inácio situava sua agência enquanto sujeito de ensaio numa intrincada rede de expectativas, incentivos e confiança inquestionável na medicina e o imperativo terapêutico. "O único documento que lembro ter assinado dizia que eu não tinha que pagar nenhuma conta." Inácio relembra o apoio com o transporte ao hospital para as infusões: "Durante dois anos, eles até me brindavam com um tanque cheio de gasolina."

Caso o tratamento funcionasse, "àqueles pacientes que quisessem continuar, foi dito que eles teriam tratamento contínuo até que morressem." Inácio e outros pacientes não podiam entender como uma empresa havia sido autorizada a iniciar um ensaio clínico e podia agora se isentar da responsabilidade legal de prover o tratamento. "Nós nos expusemos à terapia sem saber se ela iria funcionar ou não. Algum benefício a empresa teve. Nós não morremos." Quem era responsável pelo acesso ao tratamento? Quem pagaria? Qual era a condição clínica desse paciente? Todas eram questões sem respostas.

Enquanto isso, a judicialização - a recente enxurrada de demandas judiciais calcadas nas noções de acesso e direitos - se tornou uma espécie de parainfraestrutura: uma arena através da qual diversos atores e setores da saúde, públicos e privados, acabam se confrontando e realizando missões de salvamento "uma por uma". Questões mais amplas sobre a reforma do sistema de saúde, a sustentabilidade e os determinantes sociais da saúde continuam na sombra. Tudo isso está acontecendo contra o pano de fundo de um mercado incontestado e um governo nacional com política regulatória aquiescente (Biehl; Petryna, no prelo). Inácio, abandonado a um futuro distópico de um 
tratamento promissor com tecnologia de ponta, resistiu em tornar-se ele próprio um paciente litigante. Finalmente, depois de se unir a uma ação coletiva contra o Estado, o caso de Inácio foi temporariamente resolvido quando uma alta instância judiciária, através de parecer majoritário, exigiu que o fabricante da medicação provesse o tratamento a todos aqueles que não possuíam recursos. A empresa, temendo um escândalo na mídia em volta desses pacientes, acatou a decisão. Esse caso demonstra o que está em jogo no ensaio globalizado e como os seus riscos (neste caso, o risco de descontinuar acesso ao tratamento) podem ser compensados para além dos tribunais através de novas capacidades estatais inseridas no capitalismo global.

A labuta de Inácio e seus colegas se remete a um espaço onde a política falhou em reconhecer a dimensão dos riscos que acompanham o modelo comercial da experimentalidade. Instituições públicas desempenham um papel vital na arbitragem da lógica de mercado, resolvendo "impossibilidades" que pacientes e investigadores bem-intencionados enfrentam, e garantindo o acesso do cidadão aos novos medicamentos. Pesquisas de todo tipo, privadas e públicas, borram a distinção entre o experimental e o terapêutico. À medida que cresce a variedade dos experimentos, o caráter dos cuidados médicos em contextos ricos e pobres está mudando e novos instrumentos para qualificar e garantir o direito à saúde precisam ser desenvolvidos.

\section{Os desafios à frente}

Este artigo versou sobre algumas das novas geografias do capital e do poderio farmacêutico que facilitam a experimentalidade. Considerando as dimensões expatriadas e temporalidade acelerada desse fenômeno, levantei perguntas sobre a adequação das normas de proteção que vigoram nos Estados Unidos e internacionalmente, como elas são modificadas, como elas variam de lugar para lugar, e como dados são estrategicamente gerados e, por vezes, estrategicamente omitidos. Os riscos institucionais e pessoais derivados dessa expansão são desigualmente distribuídos; as metas imediatas da indústria são favorecidas. Enquanto a atenção corporativa dessa indústria é focada na transportabilidade dos dados, as incertezas do contexto e as variáveis relacionadas ao paciente são camufladas. E isso por si só, como alguns de meus informantes na indústria dos ensaios sugerem, já é um risco que pode se revelar mais 
adiante como dano. De fato, os benefícios à saúde (e não só financeiros) trazidos pela pesquisa clínica globalizada continuam tão incertos para pacientes como para consumidores e pesquisadores.

$\mathrm{Na}$ medida em que a expansão da pesquisa clínica redefine os termos da participação pública no setor privado da pesquisa biomédica, sugiro algumas recomendações. Primeiro, é preciso garantir melhores proteções para o paciente. Os protocolos éticos vigentes sobre a proteção do paciente continuam sendo muito limitados; questões envolvendo a proteção de seres humanos devem avançar para além dos procedimentos rotineiros do consentimento informado. $\mathrm{O}$ dano - como ele é produzido nos contextos mais abrangentes de experimentação - precisa ser explicitamente definido nos centros de pesquisa. Questões fundamentais como a continuidade do tratamento e o controle dos dados por patrocinadores de ensaios clínicos - questões que geralmente não são previstos nos contratos e não se articulam nos formulários de consentimento informado - também devem ser confrontados.

Em segundo lugar, os dados provenientes de ensaios clínicos devem ser vistos como um bem público, algo com um valor inestimável em termos da saúde pública, e portanto merecedor de escrutínio. Auditoria e supervisão regulatória devem vir junto com estratégias legais tornando empresas do ramo farmacêutico responsáveis pelos ensaios e pela segurança dos ensaios e dos medicamentos de maneira direta e imediata. Através da intensificação do monitoramento nacional e local e da pressão legal, diversos objetivos da saúde pública podem ser conquistados, incluindo o esclarecimento dos riscos, a censura a práticas prejudiciais e a prevenção e compensação adequadas para os efeitos adversos na medida em que afetam indivíduos e instituições de saúde. ${ }^{16}$ O financiamento federal para a avaliação de tecnologias de saúde também precisa ser reforçado para que as instituições públicas com recursos limitados possam fornecer serviços de saúde abrangentes e sustentáveis.

A experimentalidade, atualmente um empreendimento planetário para a fabricação de dados, tem consequências contraditórias. Ela pode trazer benefícios à saúde, mas ao deixar no seu rastro evidências científicas parciais, danos não antecipados e novas realidades médicas e legais, ela também pode

${ }^{16}$ Existe aqui um paralelo com o controle do tabaco enquanto estratégia de saúde pública. Ver Gostin (2007).

Horizontes Antropológicos, Porto Alegre, ano 17, n. 35, p. 127-160, jan./jun. 2011 
carregar a semente do seu próprio fracasso. Isso não é verdade apenas para o Brasil, ou Polônia, mas para os Estados Unidos e igualmente para outros países. Em 2007, o inspetor geral do Departamento de Saúde e Serviços Humanos (Department of Health and Health Services) dos EUA publicou um relatório descrevendo o fracasso da Food and Drug Administration em garantir a supervisão adequada de ensaios clínicos nos Estados Unidos. A FDA, o documento acusa, é "incapaz de identificar todos os ensaios em andamento e os centros de ensaio"; "a incerteza do momento e a falta de coordenação impedem a capacidade da FDA na condução de [...] inspeções" (Office of the Inspector General, 2007, p. ii). O relatório estima que a agência só inspecionou 1\% dos centros de ensaios clínicos entre 2000 e 2005. Além disso, as orientações e diretrizes da FDA "não refletem as práticas correntes de ensaios clínicos" (Office of the Inspector General, 2007, p. ii). Escrevendo em resposta a esse relatório crítico, o estudioso de bioética Arthur Caplan (2007) questiona: "Como pode ser que saibamos quantos porcos, sapos, ratos e macacos são utilizados em pesquisas e quem os utiliza sem sabermos o que está acontecendo com relação a seres humanos?" O relatório do inspetor geral recomenda o aprimoramento de sistemas de informação, a criação de um banco de dados sobre ensaios clínicos e um cadastro de comitês institucionais de ética, e o desenvolvimento de mecanismos de retroalimentação de pós-auditoria. Caplan considera que tais técnicas corretivas estão chegando tarde, mas repara que, sem vontade política e financiamento adequado do Congresso norte-americano, a FDA não será capaz de remediar suas falhas ou combater brechas.

Aumentar a confiança entre pesquisador e pesquisado, pacientes e médicos, é crucial para a reforma. Mas ainda mais crucial são as coletividades e possibilidades de cidadania que estão se produzindo, particularmente em relação a como as pessoas vivem com os novos investimentos experimentais que delas tiram lucro. Falhas na proteção dos mais vulneráveis são quase garantidas diante das assimetrias de conhecimento descritas neste estudo.

Traduzido do inglês por Ethon Fonseca. 


\section{Referências}

ADAMS, V.; NOVOTNY, T. E.; LESLIE, H. Global Health Diplomacy. Medical Anthropology, v. 12, n. 4, p. 315-323, 2008.

ANGELL, M. The truth about the drug companies: how they deceive us and what to do about it. New York: Random House, 2006.

BIEHL, J. Pharmaceutical governance. In: PETRYNA, A.; LAKOFF, A.; KLEINMAN, A. (Ed.). Global pharmaceuticals: ethics, markets, practices. Durham, NC: Duke University Press, 2006. p. 206-224.

BIEHL, J. Will to live: AIDS therapies and the politics of survival. Princeton: Princeton University Press, 2007.

BIEHL, J.; PETRYNA, A. Bodies of rights and therapeutic markets. Social Research, v. 78, n. 2, 2011. No prelo.

BIEHL, J. et al. Judicialisation of the right to health in Brazil. The Lancet, v. 373, n. 9682 , p. $2182-2184,2009$.

CAPLAN, A. Commentary: report paints grim picture of drug trial safety. 2007. Disponível em: <http://www.msnbc.msn.com/id/21029879/>. Acesso em: 5 out. 2007.

CENTERWATCH. State of the clinical trials industry: a sourcebook of charts and statistics. Boston: Thomson CenterWatch, 2005.

CHRISTAKIS, N. A. Ethics are local: engaging cross-cultural variation in the ethics for clinical research. Social Science and Medicine, v. 35, n. 9, p. 10791091, Oct. 1992.

COHEN, L. Where it hurts: Indian material for an ethics of organ transplantation. Daedalus, v. 128, n. 4, p. 135-165, 1999.

DELVECCHIO GOOD, M.-J. The biotechnical embrace. Culture, Medicine and Psychiatry, v. 25, n. 4, p. 395-410, 2001. 
DODIER, N. Transnational medicine in public arenas: AIDS treatment in the South. Culture, Medicine, and Psychiatry, v. 29, n. 3, p. 285-307, 2005.

DUMIT, J. When explanations rest: "good enough" brain science and the new biomental disorders. In: LOCK, M.; YOUNG, A.; CAMBROSIO, A. (Ed.). Living and working with the new medical technologies: intersections of inquiry. Cambridge: Cambridge University Press, 2000. p. 209-233.

EPSTEIN, S. Impure science: AIDS, activism and the politics of knowledge. Berkeley: University of California Press, 1996.

EPSTEIN, S. Inclusion: the politics of difference in medical research. Chicago: University of Chicago Press, 2007.

FARMER, P. Can transnational research be ethical in the developing world? The Lancet, v. 360, n. 9342, p. 1301-1302, 2002.

FISCHER, M. Emergent forms of life and the anthropological voice. Durham: Duke University Press, 2003.

GARNIER, J. P. The opportunities and challenges of globalisation: the rise of India and china. Speech at Advancing Enterprise. 2005. Disponível em: <http://www.hm-treasury.gov.uk/media/30C/C2?Dr_JP_Garnier.pdf $>$. Acesso em: 4 fev. 2005.

GEERTZ, C. Anti anti-relativism. In: GEERTZ, C. Available light: anthropological reflections on philosophical topics. Princeton: Princeton University Press, 2000. p. 42-67.

GEISSLER, P. W. et al. "He is now like a brother, I can even give him some blood" - relational ethics and material exchanges in a malaria vaccine "trial community" in The Gambia. Social Science and Medicine, v. 67, n. 5, p. 696-707, 2008.

GOSTIN, L. Global regulatory strategies for tobacco control. Journal of the American Medical Association, v. 298, n. 17, p. 2057-2058, 2007. 
GREENHOUSE, C. Hegemony and hidden transcripts: the discursive arts of neoliberal legitimation. American Anthropologist, v. 107, n. 3, p. 356-368, 2005.

IT'S A PERFECT STORM for drugmakers. Businessweek, 4 Oct. 2004. Disponível em: <http:/www.businessweek.com/magazine/content/04_40/ b3902082_mz054.htm>. Acesso em: 15 oct. 2004.

KIM, J. Y. Program in infectious disease and social change. In: THE GLOBAL Impact of Drug-Resistant Tuberculosis. Boston, MA: Harvard Medical School and the Open Society Institute, 1999.

LASAGNA, L. Prisoner subjects and drug testing. Federation Proceedings, v. 36, n. 10, p. 2349-2351, 1977.

LATOUR, B. From Realpolitik to Dingpolitik or how to make things public. In: LATOUR, B.; WEIBEL, P. (Ed.). Making things public: atmospheres of democracy. Cambridge, MA: MIT Press, 2006, p. 14-43.

LOCK, M. Twice dead: organ transplants and the reinvention of death. Berkeley: University of California Press, 2001.

MACKLIN, R. Against relativism: cultural diversity and the search for ethical universals in medicine. Oxford: Oxford University Press, 1999.

MALINOWSKI, B. Argonauts of the Western Pacific. New York: E. P. Dutton, 1961.

MARKS, H. The progress of experiment: science and therapeutic reform in the United States, 1900-1990. Cambridge: Cambridge University Press, 1997.

MARKS, H. Commentary. $3^{\text {rd }}$ Annual W. H. R. Rivers Workshop, Global Pharmaceuticals: Ethics, Markets, Practices. Harvard University, May 19-21, 2002 .

MARKS, L. Sexual chemistry: a history of the contraceptive pill. New Haven: Yale University Press, 2001. 
OFFICE OF INSPECTOR GENERAL. Department of Health and Human Services. The globalization of clinical trials: a growing challenge in protecting human subjects. Boston, 2001. Disponível em: <http://oig.hhs.gov/ organization/OIGmission.html>. Acesso em: 22 set. 2004.

OFFICE OF INSPECTOR GENERAL. Department of Health and Human Services. The Food and Drug Administration's oversight of clinical trials. Boston, 2007. Disponível em: <http://oig.hhs.gov/oei/reports/oei-01-0600160.pdf $>$. Acesso em: 30 set. 2007.

PACKARD, R. The making of a tropical disease: a short history of malaria. Baltimore: Johns Hopkins University Press, 2007.

PAREXEL.Pharmaceutical R\&D statistical sourcebook 2005/2006. Waltham, 2005.

PETRYNA, A. Life exposed: biological citizens after Chernobyl. Princeton: Princeton University Press, 2002.

PETRYNA, A. Ethical variability: drug development and the globalization of clinical trials. American Ethnologist, v. 32, n. 2, p. 183-197, 2005.

PETRYNA, A. When experiments travel: clinical trials and the global search for human subjects. Princeton: Princeton University Press, 2009.

PETRYNA, A. Pharmaceuticals and the right to health: reclaiming patients and the evidence base of new drugs. Anthropological Quarterly, v. 84, n. 2, p. 305-329, 2011.

PETRYNA, A.; KLEINMAN, A. The pharmaceutical nexus: an introduction. In: PETRYNA, A.; LAKOFF, A.; KLEINMAN, A. (Ed.). Global pharmaceuticals: ethics, markets, practices. Durham, NC: Duke University Press, 2006. p. 1-32.

RABINOW, P. Anthropos today: reflections on modern equipment. Princeton: Princeton University Press, 2003. 
RAPP, R. Testing women, testing the fetus: the social impact of amniocentesis in America. New York: Routledge, 1999.

SCHEPER-HUGHES, N. Parts unknown: undercover ethnography of the organs-trafficking underworld. Ethnography, v. 5, n. 1, p. 29-74, 2004.

UNDERSTANDING clinical trials. U.S. National Institutes of Health, 2007. Disponível em: $<$ http://clinicaltrials.gov/ct/info/whatis\#phases $>$. Acesso em: 7 ago. 2007.

Recebido em: 31/10/2010

Aprovado em: 30/11/2010 